\title{
Enhancing Quality of Higher Education through Comprehensive Continuous Evaluation
}

\author{
${ }^{1}$ Meenu Wats, ${ }^{2}$ Rakesh K. Wats \\ ${ }^{1}$ DAV College, Chandigarh, India \\ ${ }^{2}$ National Institute of Technical Teachers, Training and Research, Chandigarh,India
}

\begin{abstract}
Learning and evaluation are the two sides of the same coin. An effective evaluation methodology always results in a better and long lasting learning. To match the global standards in terms of quality of education, Government of India has introduced Comprehensive Continuous Evaluation (CCE) in its education system at the school level. The broad objective of this CCE is to judge any micro and macro level learning by students in scholastic as well as non scholastic areas. Eliminating the stress of education and making learning by doing, the CCE is proving effective amongst students at the school level, but its discontinuation at higher level (technical, professional and general education) results in wastage of efforts and dilution of previous learning. Continuation of CCE in higher education can bring desired results with least scope of resentment as the methods, target and procedures are well tested and proven and more so the target group is already exposed to the system.
\end{abstract}

\section{Introduction}

Education aims at making children capable of becoming responsible, productive and useful members of society. The education provided in the class rooms must provide that environment where the learners can analyze and evaluate their experiences, learn to doubt, to question, to investigate and to think independently. The increasingly competitive environment due to globalization in every sphere of society along with aspirations of parents place a tremendous burden and anxiety on Indian children, which in turn detriment their personal growth and development, and thus hamper the joy of learning. In the recent years, in India, there has been a growing concern for improving the quality of achievements of all learners at school as well as at higher education level. But this aim to improve the learner is not being realized due to imperfect teaching- learning processes and improper evaluation practices which are conventional and narrow in scope. The present evaluation practices especially in higher education (HE) focus on the measurement of knowledge and understanding outcome of learners. Skill evaluation and higher mental abilities are totally neglected. Though education means all round development of the child, but least attention is paid, in the present education system, on the processes involved in the assessment of students' personal development.

The higher education in India has grown in a remarkable way, particularly in the post independence period. It has an enrolment of around 14.6 million students making it the third largest system of higher education after China and USA, but these total number of students hardly represents $6 \%$ of the relevant age group, i.e., 18-23 years, which is much below the average of developed countries (47\%). The gross enrollment rate (GER) of $12.6 \%$ is way below the global average of $26 \%$. India has setup a target of $30 \%$ GER by 2020 . Thus, the Indian higher education has to focus on access, equity, accountability and quality. Though during the past 65 years Indian higher education system has shown remarkable growth but expansion in quantity has overshadowed the quality. Recognizing this fact the institutions engaged in higher education in India, now have to perform multiple roles like creating new knowledge, acquiring new capabilities and producing an intelligent human resource pool, through challenging teaching, research and extension activities. Another challenge before the country is to become a developed society within next decade. This not only requires a vibrant economy driven by knowledge, but also creation of a society where justice and human values prevail.

The challenges in higher education are no longer nation centric. They have already attained global dimensions, particularly after the trade in service has been brought under the preview of the WTO regime. Past century has witnessed an explosive growth in knowledge, development of handy tools of information and communication along with other scientific innovations. All these factors are responsible for hallmark growth in competition all through the world. Therefore, higher education system in India has to rise to the occasion urgently and reorient itself to be vibrant, competitive, meaningful and purposeful. Certain changes like national education to global education, from one time education for a few to lifelong education for all, from teacher centric education to learner centric education are the need of the hour. Because of interdependence and integration of world economy in the recent years, the Indian education system has a new role and a challenge - to provide to the nation and the world at large, skilled human power at all levels, having breadth of knowledge and confidence 
to effectively confront the social and economic realities.

To meet the above said criteria and also to match the global standards in terms of quality of education, Government of India has introduced Comprehensive Continuous Evaluation (CCE) in its education system at the school level. The broad objective of this CCE is to judge micro and macro level learning throughout the year and all through the years the students spend in the educational institution through different activities, projects and programmes. CCE primarily focuses on eliminating stress of education and making learning by doing. The scheme is thus a curricular initiative, attempting to shift emphasis from testing to holistic learning. It aims at creating good citizens possessing sound health, appropriate skills and desirable qualities besides academic excellence. It hopes to equip the learners to meet the challenges of life with success and confidence. Since its inception, CCE is proving to be an effective tool in providing quality output from the school system in India.

Keeping in view the desired outcome of CCE at the schools level, a study was conducted to identify its scope of implementation at the higher education (both technical and general education) level in India. The study also tried to identify the potential role and impact of CCE in the attainment of possible scholastic and co-scholastic competencies amongst the students of higher education. The present paper deals with the findings of this research study. The study recommends the continuation of CCE in higher education for the attainment of desired competencies for making Indian youth of world standards.

\section{Review of Literature}

Although a large amount of documents, reports, research papers, articles etc. were reviewed for the study, however, a few important are presented below:

UGC(2003) in its publication on Higher Education in India: issues, concerns and New Directions while pointing the challenges to the higher education system, especially with the country aiming to become a developed society by the year 2020 , presents areas of concern under three major headings viz. Management of Higher Education; Reorientation of Higher Education; and Quality Assurance in Higher Education. While pointing out that the challenges in higher education are no longer only nation centric but attaining global dimensions, it presents specific recommendations for charting new directions in higher education in India.

Manjula and Purushothama in their paper present that teacher training in continuous and comprehensive evaluation can significantly enhance the effectiveness of the evaluation practices of teachers.

Rosalie Flynn (2006) in his discussion paper prepared for Australian Industry Group and the Business, Industry and Higher Education Collaboration Council highlights employment outcomes of higher education. While presenting the definitions and descriptions of graduate employment skills, he explains the ways and means adopted for developing, assessing and recording these skills in the universities of Australia (3).

Goel (2006) collates recommendations made by various professional councils and researchers about core competencies for engineering graduates. He brings together the contemporary prescriptions of accreditation agencies of US, UK, Australia, Japan and Singapore. He presents a three dimensional taxonomy of competencies. While highlighting the resource based accreditation criteria of NBA in India, the recommendations of National Association of Software and Service Companies (NASSCOM) and Indian Government Task Force to examine human resource challenge for IT and IT enabled services sector have also been discussed by him. He also suggests transformation in teaching-learning and assessment processes for developing students as per the needs of present day industry (4).

Chadha \& Nicholas (2005) while discussing the integrated approach present embedded and bolt on approaches for skills development in undergraduate engineering students. Based on the case studies of four institutions/programmes using different approaches for transferable skills development, they enlist the advantages and disadvantages of the above three approaches (5).

Paul Benkeser and Wendy Newsletter (2004) present an approach of developing soft skills in students through the use of problem based learning (PBL) experiences infused throughout the curriculum. Examples of problems, tools and assessment techniques designed to promote the learning of soft skills have also been incorporated in their paper (6).

Hangman and Almekinders et.al. (2003), while suggesting the interweaving of soft skills in existing courses, describe two processes which were designed to integrate soft skills development in different academic settings. Encouraging lessons and insights for learning participation have also been presented by them (7).

Clayton et al. (2003) in their research study investigate the nature of generic skills as defined and understood in contemporary Australian and international VET context. Embedding of these skills in training packages and accredited courses, assessment and certification of these skills and the implications of the increased emphasis of these generic skills on Australian VET system have also been emphasized by them (8). 
Saxton (1996) highlights the importance of generic skills in addition to technical skills. For strengthening his view point, he reviews the findings of three researches viz. study by American Association of Community and Junior Colleges, Study by Conference Board of Canada and Curriculum Evaluation in Singapore. He presents an integrated list of generic skills based on the findings of the above studies. He also describes the strategy followed in Canada for developing these generic skills in students (9).

\section{Objectives}

The broad objectives of the study are to:

- Understand the existing evaluation system in higher education and its limitations

- Understand the concept of CCE and its scope of implementation in the higher education system

- Level of acceptance of CCE by various stakeholders of the higher education system

- Attainment of desired scholastic and coscholastic competencies amongst the students of higher education

- Role of CCE in the attainment of various competencies needed for making Indian youth of world standards

\section{Methodology}

The methodology for the study comprised of descriptive research design and accordingly a survey was conducted. For the study, the secondary data was collected from various reports, documents and research papers on assessment in higher education in India and articles in newspapers and magazines. The data was also collected from various institutions conducting higher education courses (both general education and professional education). The primary data was collected by designing a comprehensive, undisguised and partially structure questionnaire. While the quantitative data was collected through the formal survey method, the qualitative data elucidated through interviews and observations. The population for the survey comprised of 150 students and 50 teachers, professionals and experts on higher education. The collected data was edited, coded and tabulated. The tabulated data was analysed and inferences drawn to interpret the meaning. Simple statistical tools like percentages, averages etc. were used to analyse the data.

\section{Findings}

The main findings of the study are presented under following heads:

\subsection{Evaluation system in higher education in India}

Data collected during the study clearly indicates that the evaluation system in higher education is highly subjective and stressful with very less diversity in terms of assessment of varied parameters of individual's performance. During the interaction many of the students were of the opinion that evaluation system is highly inefficient with delayed results, affecting their progression to higher levels and career. As per some of the experts an effective evaluation system should be reliable, valid, flexible and efficient for meeting the demands of present day society.

Some of the main features of the present evaluation system in higher education are as follows:

- Diversity in curricula and teaching methodologies

- Lack of internationally standardized methods of evaluation

- Old conventional methods of evaluation

- Onetime or exit examination system only

- Evaluation of knowledge contents only

- Predominantly annual examination system instead of semester system

- Stressed examination system

- Stigma of pass/failed

- Quantitative marks/percentages only criterion for further admissions/ employments

- Lack of evaluation of life skills

- Cheating and leakages of question papers

- Malpractices during examination

- Existence of only external evaluation system

- $\quad$ Existence of age old curricula

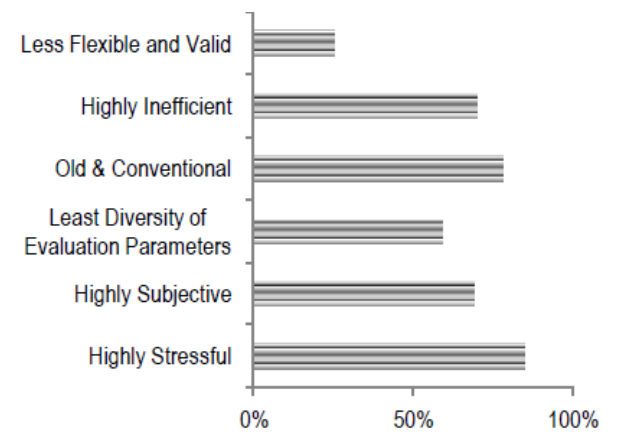

Figure 1. Evaluation system in higher education

\subsection{Focus of evaluation}

Most of the respondents of the study expressed that the focus of present system of assessment in HE is on measurement of knowledge in specific subject areas. In their view there is almost nil emphasis on 
application of knowledge and the measurement of higher level abilities of an individual. Many teachers were of the opinion that a learner must be assessed not only in cognitive domain but also in psychomotor and affective domains. A small group of professional experts pointed that along with this various age related indices and behaviors must also be incorporated in the evaluation system in higher education. However, some of the important parameters to be assessed are:

- Learn and acquire desired skills related to different subject areas

- Level of achievement in different subject areas in the requisite measures

- Develop individual learner's skills, interests, attitudes and motivation

- Changes taking place in individual's learning, behavior and progress over time

- Response to different situations and opportunities both in and out of school

- Application of learning in different situations, environment and circumstances

- Capability to work independently, collaboratively and harmoniously

- Analyze and evaluate

- Participation in social and environmental projects and causes

- Capability to retain learning over the period of time

- Ability to take risks, be adaptable and flexible

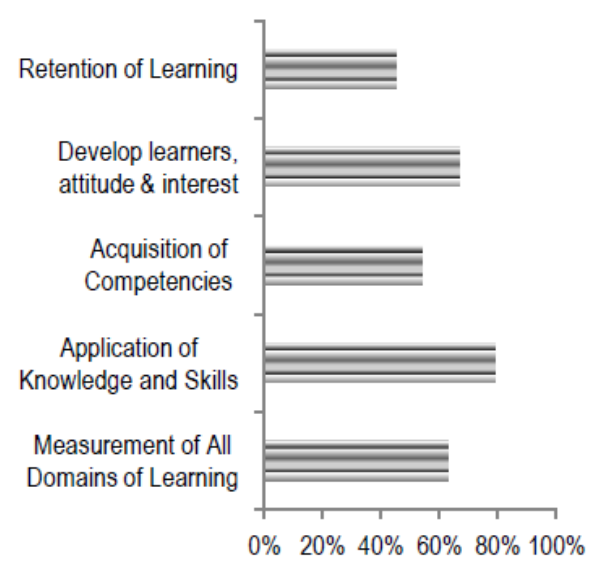

Figure 2. Focus of evaluation

\subsection{Concept of CCE}

The interpretation of the data collected during the study and the discussion with various stakeholders of the higher education system, clearly indicates that there is a need for reform in the present evaluation system as it is unable to achieve the desired objective of assessing the holistic development of individuals', which is most important attribute for success in knowledge society of the $21 \mathrm{st}$ century. Most accepted that the evaluation should not only be of knowledge component of specific subject areas at the end of session causing too much anxiety to all, but it should be of different parameters of learner's performance. A section of teachers and experts opined that different methods and modes of assessment should be used throughout the year to assess different domains of students learning. Most suggested that evaluation should be continuous and comprehensive. More than $85 \%$ of the students at the undergraduate level and teachers were aware of CCE being implemented at the school level in the country and accepted that it can be highly applicable even at the higher education level. Although they defined comprehensive and continuous terms of this evaluation system differently but the overall concept of CCE is as follows:

- The continuous aspect of CCE takes care of 'continual' and 'periodicity' aspect of evaluation

- Continual means assessment of students in the beginning of instructions (placement evaluation) and assessment during the instructional process (formative evaluation)done informally using multiple techniques of evaluation.

- Periodicity means assessment of performance done frequently at the end of unit/term (summative)

- The comprehensive component of CCE takes care of assessment of all round development of the child's personality. It includes assessment in Scholastic as well Co- scholastic aspects of pupil growth

- Scholastic aspects include curricular areas or subject specified areas, where as co- scholastic aspects include Life Skills, Co-curricular, Attitudes, and Values.

- Assessment in scholastic areas is done informally and formally using multiple techniques of evaluation continually and periodically. The diagnostic evaluation takes place at the end of unit/term test. The causes of poor performance in some units are diagnosed using diagnostic tests. These are followed up with appropriate intervention followed by retesting.

- Assessment of co-scholastic areas is done through multiple techniques on the basis of identified criteria, while assessment in life skills is done on the basis of indicators of assessment and checklists.

Thus, continuous evaluation helps in bringing awareness of the achievement to the learners, teachers and parents from time to time. They can look into the probable cause of the failure in 
achievement if any, and may take remedial measures of instruction in which more emphasis is required.

\subsection{Expected outcome of CCE}

Most of the respondents emphasized that the overall objective of comprehensive continuous evaluation is the enhancement of learning in various dimensions, making an individual successful both in career and life. According to an expert, "Learning and evaluation are the two sides of the coin. Hence effective evaluation methodology always results in a better and long lasting learning in the minds of students of any age group". Application of CCE at any level of education, school or higher, helps in achieving following targets or goals:

- It helps the educator to organize effective teaching strategies.

- It helps in regular assessment and degree of learner's progress in both scholastic and coscholastic areas. It enables the learner and educator to diagnose weaknesses and permits the educator to ascertain individual learner's strengths and weaknesses and her needs,

- It provides immediate feedback to the teacher to reframe his or her remedial teaching instructions.

- It enables the learner to assess his own strengths and weaknesses. It can also help him to motivate himself, correct errors, direct his activities towards the achievement of desired goals.

- CCE identifies areas of aptitude and interest and also changing attitudes and value system.

- It helps in making decisions for the future, regarding choices of subjects, courses and careers.

- It provides information/reports on the progress of students in scholastic and co-scholastic areas and thus helps in predicting the future successes of the learner.

Thus, the major emphasis of CCE is on the continuous growth of students ensuring their intellectual, emotional, physical, cultural and social development and therefore will not be merely limited to assessment of learner's scholastic attainments. It uses assessment as a means of motivating learners in further programmes to provide information for arranging feedback and follow up work to improve upon the learning in the classroom and to present a comprehensive picture of a learner's profile.

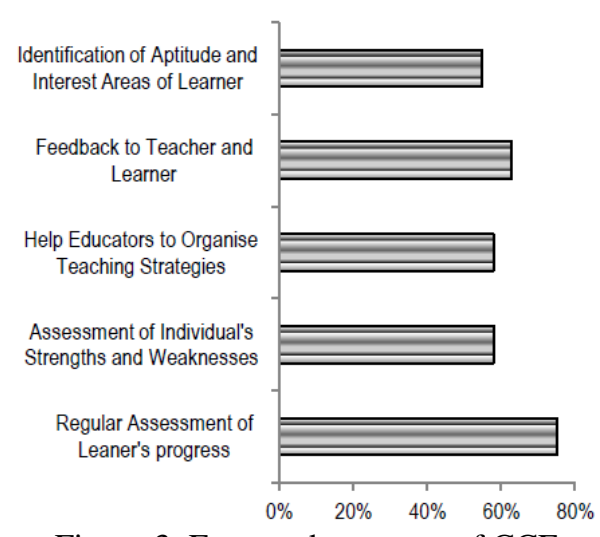

Figure 3. Expected outcome of CCE

\subsection{Tools for assessment under CCE}

For assessing various scholastic and co-scholastic abilities of the learners, various tools which can be used are as below:

Scholastic assessments: are assessed by formative and summative assessments. For both of these assessments, variety of areas are tested through the use of tools like-

- Oral questions

- Quizzes

- Projects

- Assignments

- Oral questions

- Conversation skills

- MCQ's, Short answer and Long answer questions

Co-scholastic assessment: are assessed through variety of activities, observations and interactions like:

- Co-curricular activities

- Creative and Literary Activities

- Aesthetic activities

- Scientific activities

- Life skills

- Values

- Social skills (Communication and interpersonal skills)

- Emotional skills (Dealing with emotions, stress and self awareness)

- Attitudes towards teachers, students/peers, school programmes and environment

- Thinking skills (Creative, critical, problem solving and decision making skills)

- Participation in clubs like Eco and Health and wellness clubs

Eliminating the stress of education and making learning by doing, the CCE is proving very effective amongst the students at the school level. But the irony is that this evaluation methodology has not 
been followed up in the education system at higher education levels (Professional and general higher education) with the result that all the good efforts made up to the school level go waste and the previous learning starts diluting. Although the students of higher education become academically strong but start lacking in other personal and social skills, important for achieving excellence in life.

\section{Need of CCE in higher education}

Traditionally, the Indian evaluation system has been summative- which means an examination at the end of teaching cycle. But today's children are living in a world that is constantly connected and alive outside the classroom. For the last one and a half decade higher education in India has been facing crisis. This crisis has resulted from the emergence of all kinds of mismatches between the supply and demand of knowledge in the knowledge market. Despite of the efforts of UGC, AICTE, NAAC and other professional bodies of to maintain the quality, overall standards of higher education in India deteriorating, thus reducing the value of academic degrees from most of institutes Thus there is a need of thorough reforms in the education and evaluation system in the country.

Through its capacity to provide skill and enable effective participation in the work force, education is crucial to economic adjustments. Students from institutions of higher education are churned to meet the following industry needs from the studies at the under graduate and post graduate levels:

- Ability to work in a team

- Performance focus

- Leadership skills

- Analytical ability

- Self confidence

- Risk taking

- Capability to sustain work pressure

- Flexibility

- Interpersonal relationships

- Ability to prioritise

- Dealing with an ambiguous situation

- Global mind set

- Problem solving

- Managing diversity and conflict

- Communication and personal skills

- Negotiation skills

Although the present evaluation system at higher education level has no scope to test these abilities, but the proposed benefits of CCE definitely focus on the development of these life skills along with stress free education to maximize educational output, where student is under constant observation and learning is made through experience. Through CCE even slow learners or academically non performers are assessed in other non scholastic fields. CCE can even improve dropout rates of students. CCE is designed to assess diverse parameters of students' performance and personality.

6.1. Considerations favouring CCE implementation in higher education institutions

Implementation of CCE at the school level by the Government of India is a very novel concept and has resulted in significant gains in terms of the quality of output from the school system. But this innovative concept of evaluation is bound to face some pitfalls due to some of the following constraints at the school level:

- Consumption of time

- Individual attention

- Large class strength with high pupil teacher ratio

- Teacher's perception and complacence

- Absenteeism of teacher as well as pupil

- Diversity of learners

- Monitoring and feed back

- Remediation and enrichment

- Teaching learning resources

- Uniform applicability

- Nepotism and victimization

- Switch from traditional to new method

- Maintenance of records

Despite of above mentioned constraints CCE is proving good alternative in today's world in Indian schools. It is worthwhile to point out here that most of the above said constraints do not exist in the institutions of higher education because of the very design of the system at that level. Thus, CCE can be easily introduced and accepted in Indian higher education system due to following reasons:

- Non resistance: The students coming to higher education in India are already exposed to this system in their school levels. The evaluation system will not be new to them. There is least scope of resistance to the same evaluation method at higher levels.

- Pupil teacher ratio: As the students get diversified in various streams at higher education level, the number of students in each class or section of class or group are much less than in schools. The pupil teacher ratio is $18: 1$ in universities' departments and 23:1 in affiliated colleges in India. So, the major constrain of paying individual attention gets sorted out. Personal attention is paid to each and every student in small tutorial and practical batches.

- Uniformity: Students of higher education level are neither intelligently nor academically 
heterogeneous. Thus, re-mediations as well as enrichments both are feasible.

- Resources: Institutions of higher education are rich in financial as well as material resources. Universities and their affiliated colleges are sites of rich libraries and research facilities. Learning by experimentation is much easier in such situations.

- Absenteeism: Though absenteeism is unavoidable, but in higher education institutions the time wastage does not happen. Students are free to access libraries and laboratories to prepare their seminars or other projects. They can even attend other classes of their interest with due permissions. They can make themselves busy in other institutional activities.

- Time constraint: Unlike schools where the working times, classes and teachers are all fixed, colleges and universities provide much more autonomy in working. Labs and libraries remain open for very long hours. Thus material and man both are available to students without time constraint.

- Perceptions and complacence of teachers: In institutions of higher education, subjects are taught by a team of teachers. Thus, there is least chance of nepotism, victimization and perception about any student. A student can be thoroughly observed and investigated by a team of teachers than a single one as happens in schools.

- Other than the above features, universities and colleges have some added advantages for the smooth implementation of CCE as an effective evaluation tool, like:

Highly qualified teachers

Specialized teachers in varied subjects

Availability of research resources

Availability of high-tech. labs and class rooms

$\checkmark \quad$ National and international exposure through seminars, conferences and workshops

$\checkmark \quad$ Availability of mentally mature students

$\checkmark \quad$ Availability of assistance to keep records for feed back

$\checkmark \quad$ Permanence of teaching faculty to generate experienced pool

Autonomy in adoption of innovative teaching learning modes and media

\section{Conclusions}

India has a rich heritage of Gurukul system, where students of varied strata used to get all types of teaching in residential institutions through formal as well as informal way, thus all scholastic and coscholastic domains were inculcated and assessed in each and every student. It was ancient CCE methodology. With the evolution of technology and revolution of knowledge, the length and breadth of different domains of learning are becoming endless. The combination of traditional teaching pedagogy with modernization of learning and globalised approach is one of the ways in which we can prepare our upcoming generation to become global contributors who can communicate across cultures, time and geographies. Implementation of CCE at higher education in India is felt must because most of the students from higher education courses in India are not considered fit to work at global level. Today's industry demands versatile youth with multifaceted personality. Presently there is a huge gap between industry need and the curriculum designed at higher education level. Neither the curriculum designers involve the industry nor it specifies the teaching methodologies to transfer the learning of the given subject contents. Due to lack of teaching instructions like delivering of subject contents through lecture method or seminars or group discussion or workshops or tutorials or role play, most of the times teaching in higher education restricts itself to monotonous lecture methods. This results in non-ignition of sparks in the young minds of the age group of 18-24 years and their class rooms remain non-stimulating. In this situation CCE implementation in higher education will not only result in the evolution of examination methodology to assess all domains of learning but also produce youth with desired attributes to fit into today's scenario.

\section{References}

[1] Saria Rajput, A.D. Tewari, Santosh Kumar, "Feasibility Study of Continuous Comprehensive Assessment of Primary Students" Studies in Educational Evaluation, Volume 31, Issue 4, pages 328-346.Jan. 1992.

[2] Saxton, Barrie J, "Technical Skills are not enough: Generic Skills in Technical Education", ISTE Newsletter, Vol. XVI, NO. 2, New Delhi, 1996.

[3] National Council of Educational Research and Training (2002) National curriculum Framework for School Education-2000, Published at Publication Division by the Secretary NCERT, Sri Aurobindo Marg, New Delhi, 2000.

[4] Hager, P., Holland, S., and Beckett, D., "Enhancing the Learning and Employability of Graduates: The Role of Generic Skills," The Business/Higher Education Round Table, Melbourne. 2002.

[5] "Higher Education in India: Issues, Concerns and New Directions" Printed and published by Secretary, UGC for the University Grants Commission, New Delhi, India, December 2003.

[6] Hangman, Jorgen and Almaenkinders et.al., "Developing Soft Skills in Higher Education", PLA notes, Germany, 2003. 
[7] Chadha, Deesha and Nicholas, Gill, "Teaching Transferable Skills to Undergraduate Engineering Students: Recognizing the value of Embedded and Bolt-on Approaches", International Journal of Engineering Education, Vol. 22, No. 1, Great Britain, 2006.

[8] Flynn, Rosalie, "Graduate Employability Skills: Discussion Paper," Precision Consultancy, Melbourne, Australia, 2006.

[9] Chandra, Ashoka, "Emerging Challenges in TVET in Manpower and Skill development", National Seminar on Business and Soft Skills Development in Technical Manpower, NITTTR, Chandigarh (India), 2006.

[10] Goel, Sanjay, "Competency Focused Engineering Education with Reference to IT Related Disciplines : Is the Indian System Ready for Transformation?", Journal of Information Technology Education, Vol. 5, 2006. 